\title{
Screening of marine fungal strains for laccase-like activities amenable to biotechnological applications
}

Wissal BEN ALI ( $\nabla$ wissal.BEN-ALI@etu.univ-amu.fr )

Aix-Marseille Universite https://orcid.org/0000-0003-0865-2102

Delphine Chaduli

Aix-Marseille Universite

David Navarro

Aix-Marseille Universite

Christian Lechat

ASCOfrance

Annick Turbé-Doan

Aix-Marseille Universite

Emmanuel Bertrand

Aix-Marseille Universite

Craig B. Faulds

Aix-Marseille Universite

Giuliano Sciara

Aix-Marseille Universite

Laurence Lesage-Meessen

Aix-Marseille Universite

Eric Record

Aix-Marseille Universite

Tahar Mechichi

Universite de Sfax ecole nationale d'ingénieurs de Sfax

Research article

Keywords: marine-derived fungi, Trichoderma asperellum, laccase-like activity, laccase-like multicopper oxidases (LMCO), dyes

Posted Date: January 22nd, 2020

DOI: https://doi.org/10.21203/rs.2.21616/v1

License: (c) (7) This work is licensed under a Creative Commons Attribution 4.0 International License.

Read Full License 
Page $2 / 28$ 


\section{Abstract}

Background Environmental pollution is one of the major problems that world is facing to date. Several approaches are been studied and oxidative enzymes from microbial organisms represent an eco-friendly and cost-effective processes, amenable to biotechnological applications, as for instance industrial dye decolorization. The aim of this study was to screen marine-derived fungal strains isolated from three coastal areas in Tunisia, to identify laccase-like activities, and to produce and characterize active fungal secretomes of interest for dye decolorization.

Results Following the screening of twenty fungal strains isolated from the harbours of Sfax and Monastir (Tunisia), five strains were identified displaying laccase-like activities. Molecular based taxonomic approaches allowed us to identify these strains as belonging to the species Trichoderma asperellum , Stemphylium lucomagnoense and Aspergillus nidulans. Among these five isolates, one T. asperellum strain ( T. asperellum 1) gave the highest level of secreted oxidative activities, and as such it was chosen for further studies. Optimization of the growth medium for liquid cultures was first studied to improve the level of laccase-like activity in culture supernatants. Finally, T. asperellum 1 secretome allowed decolorizing different synthetic dyes belonging to diverse dye families, in the presence or absence of 1hydroxybenzotriazole (HBT) as a mediator.

Conclusions The optimal growth conditions to produce laccase-like active secretomes from $T$. asperellum 1 were $1.8 \mathrm{mM}$ CuSO 4 as an inducer, $1 \% \mathrm{NaCl}$ to mimic seawater environment and $3 \%$ sucrose as a carbon source. T. asperellum 1 secretome was effective to decolorize different synthetic dyes belonging to diverse chemical classes, and the presence of HBT as a mediator improved the decolorization process.

\section{Background}

Water pollution represents a serious environmental issue, and it is reported that many industries dump wastes into rivers, lakes, pounds, and water streams in an attempt to hide them from Environmental Protection Agencies [1]. Many studies have recently been focusing on using microbial enzymes to transform and detoxify pollutants [2,3]. Compared to bacteria, fungi are considered to be more robust organisms and generally more tolerant to high concentrations of pollutants. In addition, they produce high levels of extracellular enzymes with large industrial potential in eco-friendly and cost-effective processes [4].

Most of the fungi studied to date are isolated from forests and other terrestrial environments, while few studies have focused on the exploration of marine fungal diversity. Nevertheless, marine environments are extremely complex and host a broad spectrum of fungal species. Although some novel fungal genera have been identified in marine environments and characterized, most marine-derived fungi seem to be related to terrestrial fungi, such as Fusarium sp., Aspergillus sp., Cephalosporium sp. and Penicillium sp. Marine-derived fungi have been shown to be present in various habitats such as coastal areas, marine sediments and deep sea, but also associated to sponges, microalgae, fish, and mangrove wood. Finally, 
they have been classified as either obligate or facultative marine fungi. The formers are those that grow exclusively in a marine habitat, whereas facultative marine fungi are those from fresh water or terrestrial origin that are able to thrive in marine environments $[5,6]$. As a result, the term "marine-derived fungi" is often used because most of the fungi isolated from marine samples are not demonstrably classified as obligate or facultative marine microorganisms [7]. Recently, an online database was created to get more insight into the taxonomy of marine-derived fungi (www.marinefungi.org), with a full description and an up-to-date classification of all known marine fungal species [8]. The interest in discovering the biodiversity of marine-derived fungi is not merely taxonomic though. In fact, within each marine habitat, local microbial communities have adapted to seawater environmental conditions, and their enzymes are, therefore, potentially very attractive for biotechnological applications, due to their properties, including thermostability, as well as salt and $\mathrm{pH}$ tolerance. Not astonishingly, due to their adaption to low temperature, high salinity, high pressure and oligotrophic conditions typical of the marine environment, marine-derived fungi are a promising source of novel bioactive metabolites that are not found in terrestrial strains of the same species, including enzymes and LMCOs [9].

Laccase-like multicopper oxidases (LMCOs, EC 1.10.3.2), constitute a multigenic family of multicopper oxidases that is distributed across bacteria, fungi and plants. Often simply referred to as "laccases", they catalyse at a mononuclear copper center $\mathrm{T} 1$ the one-electron oxidation of four substrate molecules including substituted phenols, arylamines and aromatic thiols, to the corresponding radicals, with the simultaneous reduction at a trinuclear copper center T2/T3 of molecular oxygen to water [10]. LMCOs represent an outstanding group of oxidoreductases, since they have low substrate specificity. Beyond their active copper cluster, they do not need the addition of heterogenously added cofactors for their activity, and their co-substrate, oxygen, is usually present in their environment. Most of these enzymes are naturally secreted and thus generally exhibit a considerable stability in the extracellular environment. The high level of inducible expression of laccase-encoding genes in most fungal species also contributes to their attractiveness in biotechnological applications [3]. New sources of LMCOs with special properties, such as high-redox potential, high salt and temperature tolerance, or cold adaptivity, are desired for industrial applications. A large variety of fungal strains isolated from several sea grasses, algae and decaying wood samples possess the ability to produce LMCOs [11]. Mabrouk et al. [12] have isolated Trematosphaeria mangrovei from a mangrove ecosystem which produces a laccase in significant quantities. A thermo-stable, metal-tolerant laccase is produced by the marine-derived fungus Cerrena unicolor [13]. Several researchers have isolated laccase-producing fungi from different sources, and notably among the species Trichoderma harzianum, Trichoderma atroviride, Trichoderma longibrachiatum, Trametes versicolor, Lentinus tigrinus, Trametes pubescens, Cyathus bulleri, Paecilomyces sp., Phanerochaete chrysosporium, Lentines edodes, Pleurotus ostreatus, Ganoderma lucidum, Alternaria tenuissima and Trichoderma sp. [11]. Because fungi from marine environments have adapted to grow under high saline (15-34 ppt (parts per thousand)) and alkaline conditions, the LMCOs they express are of potential interest for the bioremediation of high-salt et alkaline effluents, such as those from from the pulp and paper, tanning and textile industries [14]. 
Nevertheless, reports focusing on the identification of marine-derived LMCOs are still quite limited to date. In order to pave the way to the identification of novel LMCOs, the main purpose of this study was to isolate and identify new marine-derived fungal strains, to screen them for their capacity to produce laccase-like active secretomes, and to determine for a few selected strains the optimal growth conditions for obtaining high levels of laccase-like activities.

\section{Results}

\section{Isolation and identification of fungal strains}

Marine-derived fungi from various marine areas of the Tunisian coast were isolated and screened. Twenty fungal strains were isolated up to the stage of monomorphic cultures in solid medium. Among them, five showed positive oxidative activity on both DMP and ABTS added as substrates to solid medium in petri dishes.

The morphological aspect of the five isolates was observed using an optical microscope and cultures of the pure isolates were run for molecular analysis relying on primers directed against the DNA sequences of the ITS region. Based on both approaches, two strains were identified as belonging to the species Stemphylium lucomagnoense and Aspergillus nidulans. Phylogenetic trees based on ITS sequences were constructed to find the relationships of the newly isolated strains with previously characterized species (Fig. 1 and 2). As shown in fig. 1, phylogenetic analysis using ITS-derived sequences shows that our isolate, Stemphylium sp. CIRM-BRFM 2667 clusters closely with Stemphylium vesicarium and $S$. Iucomagnoense. Based on morphological treats of the species S. lucomagnoense, notably the shape and size of the asexual spores [15], we propose to affiliate our strain to S. Iucomagnoense. Similarly, we propose that our isolate CIRM-BRFM 2671 belongs to the species A. nidulans (Fig. 2). The obtained sequences were deposited at Genbank under the accession number MK691703 and MK691704 for $S$. Iucomagnoense and $A$. nidulans respectively. The affiliation of three other strains to the genus Trichoderma was established based on sequences of the TEF-1 a region (Fig. 3). The three isolates (CIRMBRFM 2668, 2669 and 2670) are clustered in a clade including exclusively 23 Trichoderma species, with high bootstrap values for each branch (Fig. 3). The related sequences, corresponding to strains Trichoderma sp 1, Trichoderma sp 2 and Trichoderma sp 3 were deposited under the accession numbers MK966034, MK966035 and MK966036, respectively. It can be inferred from the phylogenetic tree that the closest strain to isolates Trichoderma sp 1, Trichoderma sp 2 and Trichoderma sp 3 is the species Trichoderma asperellum.

\section{Production of fungal secretomes with laccase-like activity}

Laccase-like activities of the five selected isolates were studied starting from liquid cultures. Firstly, we confirmed that the activity was not related to heme-containing peroxidase activities by adding either $\mathrm{H}_{2} \mathrm{O}_{2}$ or alternatively catalase to the reaction assay. Under these two conditions, no increase or no reduction in the activity was observed, respectively, suggesting that the activity is therefore most probably correlated 
to LMCO enzymes. Considerable laccase-like activities were measured with $T$. asperellum 1,2 and $3, A$. nidulans and $S$. Iucomagnoense. produced lower activity levels. The highest laccase-like activities were detected with T. asperellum 1 and 2 and accounted for $185 \mathrm{U} \mathrm{L}^{-1}$ (Fig. 4A). Laccase-like activities increased during the first $48 \mathrm{~h}$ and then reached a plateau. Due to the fact that the five selected strains were isolated from marine environments, we assumed that they are biologically adapted to live in saline conditions. Therefore, we tested if the levels of secreted laccase-like activities were affected by adding $1 \%$ $\mathrm{NaCl}$ to the culture media (Fig. 4B). T. asperellum 1 yielded the highest level of laccase-like activities (193 $\mathrm{U} \mathrm{L}^{-1}$ ). For the three $T$. asperellum strains, secreted laccase-like activity sharply decreased after $48 \mathrm{~h}$ to finally reach a plateau at around $120 \mathrm{UL}^{-1}$, less than in cultures without $\mathrm{NaCl}$, suggesting that the responsible enzymes might be sensitive to $\mathrm{NaCl}$. Interstingly, laccase-like activity was significantly induced by adding $\mathrm{NaCl}$ to $S$. lucomagnoense cultures, yielding $110 \mathrm{U} \mathrm{L}^{-1}$ (4-to-5 more than the $25 \mathrm{U} \mathrm{L}^{-1}$ obtained without $\mathrm{NaCl}$ ). Because of the high levels of laccase-like acivity in its secretome, T. asperellum 1 was chosen for further studies.

\section{Effect of sea salt and different concentrations of $\mathrm{NaCl}$ on laccase-like activities in Trichoderma asperellum 1 cultures}

Different concentrations of $\mathrm{NaCl}(0,1,2,3,4$ and $5 \% \mathrm{w} / \mathrm{v})$ were added to the medium used for $T$. asperellum 1 cultures, and laccase-like activity in the resulting supernantant was quantified. The results are duplicated in fig. 5A. As previously observed, the addition of $1 \% \mathrm{NaCl}$ induced the production of laccase-like activities, with an optimum of $235 \mathrm{U} \mathrm{L}^{-1}$ after three days of fungal culture and laccase-like activity decreased instead at higher concentrations of $\mathrm{NaCl}$. Natural seawater does not only contain sodium chloride, but also important quantities of chloride and sulfate salts of calcium, potassium, and magnesium, and substantially lower amounts of many trace elements. As such, addition of $1 \%$ sea salt to T. asperellum 1 cultures was tested too (fig $5 \mathrm{~B}$ ). In these conditions no real effect on laccase-like activity was found, with a $160 \mathrm{UL}^{-1}$ maximum at day 4 , against $170 \mathrm{UL}^{-1}$ at day 3 with $0 \% \mathrm{NaCl}$. Interestingly, however, with sea salt laccase-like activity did not decrease after $72 \mathrm{~h}$, remaining stable up to $200 \mathrm{~h}$ growth.

\section{Influence of $\mathrm{CuSO}_{4}$ and of different carbon sources on laccase-like activity in Trichoderma asperellum 1}

To study the effect of $\mathrm{CuSO}_{4}$ on secreted laccase-like activity, different concentrations of $\mathrm{CuSO}_{4}(800 \mu \mathrm{M}$, $1000 \mu \mathrm{M}, 1800 \mu \mathrm{M}$ and $2000 \mu \mathrm{M}$ ) were supplemented to the M7 medium used for T. asperellum 1 cultures. The results, reported in fig. 6 , indicate that laccase-like activity increased significantly in the supernatant when cultures were supplemented with $\mathrm{CuSO}_{4}$. These increments were dose-dependent and significantly higher at around $2000 \mu \mathrm{M} \mathrm{CuSO}_{4}$, as clearly visible at $72 \mathrm{~h}$, when activity was $\left(170 \mathrm{UL}^{-1}\right)$ was more than 3 times higher than in cultures without $\mathrm{CuSO}_{4}\left(50 \mathrm{U} \mathrm{L}^{-1}\right)$.

Carbon sources are also known to strongly affect the levels of secreted fungal laccase-like activities. For this reason, we tested adding $3 \%$ of either sucrose, glucose or starch to the M7 production medium (Fig. 
S1 Supplementary data). Our results indicate that $3 \%$ sucrose resulted in higher levels of laccase-like activity $\left(270 \mathrm{U} \mathrm{L}^{-1}\right)$ in the resulting supernatant.

\section{Decolorization of synthetic dyes}

asperellum 1 secretome was prepared in the optimized production medium ( $\mathrm{M} 7$ containing $1 \% \mathrm{NaCl}, 3 \%$ sucrose and $1.8 \mathrm{mM} \mathrm{CuSO}_{4}$ ). The decolorization ability of the culture supernatant was tested on five different dyes, belonging to three different dye families (reactive, azo and anthraquinone). The secretome was incubated in the presence of five dyes (50 $\mathrm{g} \mathrm{m} \mathrm{mL}^{-1}$ each) namely Remazol Brilliant Blue R (RBBR), Reactive Black 5 (RB5), Direct Red 75 (DR75), Acid Orange 51 (A051) and Turquoise Blue (TB) for $48 \mathrm{~h}$. Results showed that the presence of HBT, as observed for most laccases and LMCOs [16], improves the decolorization process, probably by facilitating electron transfert between oxidative enzymes from the secretome and the substrate dye molecules. Fig. 7 shows that in all cases HBT improves the decolorization efficiency of the $T$. asperellum 1 secretome, but only with RB5 it was necessary. Laccase activity differences on different substrates may depend on substrate redox potential and steric match between the substrate and the enzyme active site structures, as observed for most laccases [17]. RB5 was hardly decolorized in the absence of mediator (only $9 \%$ decolorization) whereas in $24 \mathrm{~h}$ after addition of HBT the decolorization was increased from $9 \%$ to $90 \%$. With RBBR, DR75 and TB, the decolorization was increased with the use of HBT from 60 to $80 \%$, while for A051 $5 \%$ only of additional decolorization was achieved (from 75 to $80 \%$ ). Finally, our study shows that, as observed for laccases, the addition of HBT enhances decolorization at different extents depending on the dye to oxidize.

\section{Discussion}

Fungi are recognized for their aptitude to produce a large variety of extra-cellular enzymes [18]. However, most of the fungi studied to date are isolated from forests and other terrestrial environments, while very few studies have focused on the exploration of marine fungal diversity. A large proportion of the diversity of marine-derived fungi would have originated from their terrestrial counterparts, with the appearal of strains able to live in marine harsh environments (high pressure, low temperature, oligotrophic nutrient, high salinity, etc.) $[19,20]$. These specific conditions are responsible for the significant differences between the enzymes generated by marine microorganisms and their homologues from terrestrial counterparts [21]. Finally, marine-derived microorganisms have been studied to exploit their potential to generate new natural products and to degrade plant biomass [22].

In this study, twenty marine derived fungi were isolated from Tunisian marine biotopes and five of them were selected for their oxidative profile on DMP and ABTS. These five strains were identified as ascomycetes belonging to the species Aspergillus nidulans, Stemphylium lucomagnoense and Trichoderma asperellum (three strains belonging to the latter species). Among these marine strains, Aspergillus nidulans, anamorph of Emericella nidulans, is an important model ascomycete for eukaryotic genetics. A few studies are dedicated to marine-derived A. nidulans species, such as two relatively recent works reporting on the production of molecules of interest: melanin precursors with UVB protective 
properties [23] and antitumor alkaloids [24]. Another strain identified in this study belongs to the phylum ascomycetes (Dothideomycetes Pleosporales, Pleosporaceae) and more precisely to the Stemphylium genus, that encompasses worldwide distributed saprophytes and plant pathogens affecting a variety of agricultural crops. Molecular analysis branched Stemphylium sp. with both S. vesicarium and Stemphylium lucomagnoense in the phylogenetic tree, but morphological treats confirmed that the isolated species is S. lucomagnoense, anaphorm of Pleospora lucomagnoense. To date, only two studies have been focusing on marine-derived Pleospora. The first deals with the production of antimicrobial compounds [25] and the second with phylogeny of Pleospora gaudefroyi [26].

Previously, a number of molecular markers have successfully been used for the taxonomic identification of fungal genera and species, and ITS rDNA region has been often considered as a marker of choice for the fungal kingdom [27]. However, sequencing of the TEF-1a region is considered as a sensitive tool for identification in mycology with superior resolution then ITS, e.g. when studying the genus Trichoderma [28]. In this study, TEF-1a sequence-based phylogeny suggests that the most phylogenetically related species to our three isolates Trichoderma sp 1,2 and 3 is Trichoderma asperellum, a fungus which is naturally found in soils [29]. Even if Trichoderma species are usually found in terrestrial habitats, some isolates were collected from marine environments, where they live in association to algae [30] and sponges [31], in coastal sediments [32], or as endophyte in mangroves [33]. Among these marine-derived species we found T. asperellum wich was further studied for its production of secondary metabolites, such as sesquiterpenes [34] and antibacterial peptides [35].

Different Trichoderma species were extensively studied as sources of cellulases, but also oxidases such as LMCOs [36]. This was the case, for instance, with the terrestrial species Trichoderma reesei [36], T. harzianum and T. longibrachiatum [37], as well as for the marine-derived Trichoderma sp. [38]. Moreover, a terrestrial T. asperellum secretome producing oxidases including LMCOs was applied to degrade polycyclic aromatic hydrocarbons in soil [39]. In our study, the secretomes of five fungal isolates showed different amounts of laccase-like activities, in liquid cultures and eventually under saline conditions. The highest laccase-like activity was observed with the strain $\mathrm{T}$. asperellum 1 , in cultures with as well as without $1 \% \mathrm{NaCl}$. For comparison, while marine-derived A. sclerotiorum produced $9.26 \mathrm{U} \mathrm{L}^{-1}$ laccase-like activity after 7 day-culture in $3 \%(\mathrm{w} / \mathrm{v}) \mathrm{NaCl}$, for T. asperellum 1 about $190 \mathrm{UL}^{-1}$ were obtained. In another study [40] optimization of laccase-like activity levels from Trichoderma sp. grown in $0.5 \% \mathrm{NaCl}$ yielded approximately $2000 \mathrm{U} \mathrm{L}^{-1}$, but activity was assayed using o-tolidine instead of ABTS as a substrate, and as such those results are not directly comparable with ours. The finding of laccase-like activities from fungal cultures grown in $\mathrm{NaCl}$-containing media could be benifical for industrial and biotechnological processes in which saline conditions are high [41]. In our study, we show that high levels of salt-tolerant laccase-like activity could be spot out using synthetic dyes as substrates. These findings pave the way to the discovery of novel biocatalysts for the textile industry, whose effluents contain not only dyes, but also high salt concentrations. Secretome and enzyme characterization will then be the next step of our research. 
To maximize the levels of laccase-like activity in T. asperellum 1 cultures, we evaluated the effect of different concentrations of $\mathrm{NaCl}$ and known inducers, such as $\mathrm{CuSO}_{4}$ and three carbon sources. These parameters in fact can affect the productivity of various oxidases secreted in the culture medium, due to an inhibition of fungal growth or to effects on enzyme stability and activity, possibly in relationship to protein surface charges and to perturbation of global or local protein folding [42]. In our study, higher levels of laccase-like secreted activity were found when $1 \% \mathrm{NaCl}$ was added to $\mathrm{T}$. asperellum 1 cultures. Above this concentration, activity gradually decreased with increasing $\mathrm{NaCl}$ concentration. The effect of $\mathrm{NaCl}$ was also studied for other marine fungi like Cerrena unicolor isolated from mangroves [43], and was shown to enhance laccase activity in fungal culture supernatants. Similarly, by adding sea salt to T. asperellum 1 cultures, we obtained an increase of the supernantant oxidase activity in time, with a maximum at $75 \mathrm{~h}$, like with $\mathrm{NaCl}$, but no decrease afterwards, unlike with $\mathrm{NaCl}$. In previous studies we demonstrated the activation by sea salt of two LMCOs from the mangrove fungus Pestalotiopsis sp. [44], while LMCO from Trematosphaeria mangrovei lost $50 \%$ of its activity in $1 \% \mathrm{NaCl}$ [12]. Salt-adapted enzymes are generally characterized by highly negative surface charges that are assumed to contribute to protein stability in extreme osmolytic conditions [45]. Copper has been reported to be a strong laccase inducer in several fungal species [46], [47]. It has been also reported that the increase in activity is proportional to the amount of copper added [48]. In our study, optimal $\mathrm{CuSO}_{4}$ concentration was $1800 \mu \mathrm{M}$ for T. asperellum 1 cultures, yielding about $173 \mathrm{UL}^{-1}$ laccase-like activity. These results are in agreement with previous ones [49], showing optimum LMCO activity $\left(32.7 \mathrm{U} \mathrm{mL}^{-1}\right)$ in Pestalotiopsis sp. cultures with $2.0 \mathrm{mM} \mathrm{CuSO}_{4}$, and activity decrease above this concentration. Nakade et al [50] reported that the best $\mathrm{CuSO}_{4}$ concentration for LMCO production in Polyporus brumalis was $0.25 \mathrm{mM}$. CuSO ${ }_{4}$ induction of LMCOs is related to the active site architecture of these enzymes, which contain generally 4 copper atoms per polypeptide. Copper addition to the culture medium was also reported to induce laccase gene transcription [51]. In addition, it has been reported that copper could be toxic as it interacts with nucleic acids, proteins, enzymes and metabolites associated with major cell functions, explaining why $\mathrm{CuSO}_{4}$ concentration should be tested case by case [51]. Several studies have proved that the choice of carbon sources affects the production of ligninolytic enzymes [52]. The purpose of glucose supplementation to lignocellulose for fungal cultures has two reasons. First, it promotes the growth and rapid establishment of the fungus within the solid raw material. Second, the fungus needs an additional, easily metabolizable carbon source to sustain lignin degradation from lignocellulosic substrates [53]. In our study, sucrose is the best substrate for secreted laccase-like activity from T. asperellum 1 cultures $\left(290 \mathrm{U} \mathrm{L}^{-1}\right)$, as it has previously been showed for Arthrospira maxima [54].

Industrial dyes usually have a synthetic origin and complex aromatic structures which make them highly resilient and more difficult to biodegrade [55]. Reactive dyes, for exemple, contain chromophoric groups such as azo, anthraquinone and others. Most of these dyes are not toxic by themselves, but after release into aquatic environments they may be converted into potentially carcinogenic amines that have an impact on the ecosystem downstream from the mill [56]. Currently employed physico-chemical methods were showed to have some serious limitations, such as high cost, high salt content utilization, and problems related to disposal of concentrate $[57,58]$. In this regard, considerable focus has been placed 
on developing biological processes, because they are more effective compared to more conventional, physico-chemical methods [56]. The production of LMCOs from marine-derived ascomycetes, zygomycetes and basidiomycetes has been poorly investigated [41,59]. Similarly, to our knowledge, only one work reports on the application of LMCO-containing secretomes from a marine Trichoderma to degrade synthetic dyes [40], one describes the production of laccase from marine-derived Aspergillus sclerotiorum [59] and no work is available on LMCOs derived from Stemphylium species. In this study, the dye decolorization ability of $\mathrm{T}$. asperellum 1 secretome was tested against five different industrial synthetic dyes: Reactive Black 5 (RB5), Remazol Brilliant Blue R (RBBR), Direct Red 75 (DR75), Turquoise Blue (TB) and Acid Orange 51 (A051). These dyes belong to different dye families: reactive, azo and anthraquinone. It is generally observed that the extent of decolorization is known to depend on the enzyme properties (and as such, the biological source) as well as the chemical properties, structure and size of the dye molecule $[2,60]$. Due to its high molecular weight, for example, sulfonated azo dyes are unable to pass through the cell membrane, and therefore degradation of these dyes must occur extracellularly. The role of redox mediators in an azo bond detoxification has also been shown before [61]. For instance, it has been reported that the addition of the mediator HBT to the LMCO-containing secretome of Paraconiothyrium variabile enhanced the decolorization of RB5, RBBR, DR75 and TB [62].

In a previous study we investigated RBBR decolorization by the culture filtrate of the terrestrial ascomycete Trametes trogii and by the LMCO isolated from it [63]. The purified LMCO decolorized up to $97 \%$ of a $100 \mathrm{mg} \mathrm{L}^{-1}$ dye solution, with only $0.2 \mathrm{U} \mathrm{mL}^{-1}$ enzyme. In our test conditions, we reached comparable results (60-80\% decolorization) with T. asperellum 1 culture supernatant, with or without HBT. In general, different marine strains are able to degrade RBBR to different extents, for exemple Flavodon flavis degraded RBBR to more than 90\% [64] while Cerrena unicolor only to 46\% [65].

Biodegradation of RB5 was investigated using the secretome of the ascomycete Trichoderma atroviride F03 yielding $91.1 \%$ decolorization without mediators [66]. Three products of this biodegradation reaction (1, 2, 4-trimethyl benzene, 2, 4-ditert butylphenol and benzoic acid-TMS derivatives) were identified, confirming the validity of enzymatic treatment without generating aromatic amines, which are higly toxic [66]. In comparison, the T. asperellum 1 secretome allowed attaining only $10 \%$ of RB5 decoulorization without HBT, and up to $80 \%$ in the presence of mediator.

A051, is a water-soluble anionic azo dye. Typically containing one to three sulfonic groups, it is widely applied to colour wool, silk and polyamide. The nature and level of toxicity of A051 has not been well established yet [67], but sulfonated azo dyes (including naphthalene sulfonic acids, naphthols, naphthoic acids, benzidines, etc), and particularly benzidines are in the focus of attention because of their carcinogenicity [67]. A051 degradation by crude LMCO from Trametes trogii grown in solid cultures on sawdust has been investigated [67] and above $88 \%$ decolorization in the presence of HBT was achieved. Our results show that with $\mathrm{T}$. asperellum 1 culture supernatant, instead, HBT was not essential for achieving A051 decolorization. To our knowledge, this is the first report of A051 decolorization without the need of laccase mediators. 
To date, only a few studies have dealt with decolorization of the phthallocinine dye TB. Plácido et al. showed that Leptosphaerulina sp. effectively decolorized TB and two real effluents from textile industries [68]. This decolorization was catalyzed by the production of significant quantities of LMCO $\left(650 \mathrm{UL}^{-1}\right)$ and manganese peroxidase $\left(100 \mathrm{UL}^{-1}\right)$. Leptosphaerulina sp. enzymatic extracts exhibited decolorizing activity when ABTS was added as mediator. Similarly, the secretome of T. asperellum 1 showed maximum TB biodegradation capacity when HBT was added.

Remarkably high levels of DR75 degradation (95-100\%) were achieved after $120 \mathrm{~h}$ incubation with Penicillium oxalicaum culture supernatant [69]. In that study, high levels of manganese peroxidase activity $\left(659.4 \pm 20 \mathrm{UL}^{-1}\right)$ were measured in the P. oxalicaum secretome, indicating the involvement of heme peroxidases in the decolorization process. In our study, instead, no peroxidase activity was detected in T. asperellum 1 secretomes, suggesting for the first time, to our knowledge, that LMCO-catalyzed DR75 degradation takes place instead.

Further studies will be necessary to get further insight into the enzymatic mechanisms deployed by marine-derived fungi to cope with their environment. It will be necessary to identify the key enzymes secreted by T. asperellum 1 growing in saline conditions, as well as to produce and characterize them, with a focus on salt-depence and the structure-function relationship underlying enzyme properties. In order to asses the potential of T. asperellum 1 secretomes or enzymes for enzymatic bioremediation of textile effluents, finally, the degradation products of enzymatically treated model dyes and industrial samples should be precisely identified and characterized, and their impact on human health and environment should be determined.

\section{Methods}

\section{Sample collection}

The environmental samples (woods immersed in seawater, seaweeds, marine plants, pieces of nets) used in this study were collected from four different Tunisian marine biotopes: the fishing port, the Sidi Mansour and the Casino sites at Sfax, and the polluted Khnis site at Monastir. These sites were chosen because of their pollution, in an attempt to isolate fungal strains resistant to polluted water, and enzymes able to work in the presence of several contaminant species and aromatic compounds. The samples were collected in sterile tubes using a sterile spatula and stored at $4{ }^{\circ} \mathrm{C}$ until use.

\section{Isolation of fungi}

Small pieces of sample were inoculated on 3.9\% (w/v) potato dextrose agar (PDA) (Sigma-Aldrich, SaintQuentin-Fallavier, France) and 1.8\% (w/v) malt extract (Sigma-Aldrich), with $3.4 \%(\mathrm{w} / \mathrm{v}) \mathrm{NaCl}$ and $0.1 \%$ $(\mathrm{w} / \mathrm{v})$ chloramphenicol to prevent bacterial growth and incubated at $30^{\circ} \mathrm{C}$ for 3 days until fungal growth was observed. Apparently monomorphic cultures obtained after at least two transfers onto fresh agar plates were further authenticated using molecular tools to check strain purity and identity. 


\section{Preliminary screening of the isolates}

A preliminary screening for oxidative activity was performed in PDA plates supplemented with $2 \mathrm{mM}$ 2,6dimethoxyphenol (DMP) or 200 mM 2,2'-azino-bis-(3-ethylbenzthiazoline-6-sulfonic acid) (ABTS) as substrates. The plates were incubated at $30^{\circ} \mathrm{C}$ for 3 days and the presence of orange and purple halos around the mycelium was considered as the positive sign of substrate oxidation.

\section{Molecular identification (DNA extraction, PCR and sequencing)}

The mycelium of selected strains was obtained by liquid culture in $50 \mathrm{~mL}$ flasks in malt extract medium for 3 days. Genomic DNA was isolated from $40-80 \mathrm{mg}$ of mycelium powder using GeneJET Genomic DNA Purification Kit (Thermo Scientific, Waltham, USA) following the manufacturer's instruction. DNA concentration was estimated at $260 \mathrm{~nm}$ using a Nanodrop 2000 (Thermo Fisher Scientific, Wilmington, USA).

The extracted DNA was used as the template in a PCR to amplify the partial sequences of two DNA loci, namely the internal transcribed spacer region (ITS) and the translation elongation factor1a region (TEF1a). The primers used for the amplification were ITS5 (5'- GGAAGTAAAAGTCGTAACAAGG-3') and ITS4 (5'-TCCT-CCGCTTATTGATATGC-3') [70] for the former (used for the Aspegillus and Stemphylium isolates) , and TEF1a-983-F-CF2 (5'-GCYCCYGGHCAYCGTGAYTTYAT-3') and TEF1a-2218-R-CR2 (5'-

ATGACACCRACRGCRACRGTYTG-3') [28] for the latter (used for the Trichoderma strains). PCR was performed using the Expand High Fidelity Kit (Roche Diagnostics $\mathrm{GmbH}$, Mannheim, Germany) in $5 \mu \mathrm{L}$ buffer $(100 \mathrm{mM}$ Tris $\mathrm{HCl}, 150 \mathrm{mM} \mathrm{MgCl} 2$ and $500 \mathrm{mM} \mathrm{KCl})$ with $1.5 \mathrm{mM} \mathrm{MgCl}_{2}, 0.25 \mu \mathrm{M}$ of each primer, 1 $\mu \mathrm{L}$ of deoxynucleoside triphosphate ( $200 \mu \mathrm{M}$ of each dNTP), $1 \mu \mathrm{L}$ of DNA (about $100 \mathrm{ng}$ ), and Taq DNA polymerase $\left(25 \mathrm{mU} . \mu \mathrm{L}^{-1}\right)$, in a final volume of $50 \mu \mathrm{L}$. Cycling parameters were $94^{\circ} \mathrm{C}$ for $2 \mathrm{~min}$ followed by 40 cycles of $94^{\circ} \mathrm{C}$ for $15 \mathrm{~s}, 51^{\circ} \mathrm{C}$ for $30 \mathrm{~s}$, and $72{ }^{\circ} \mathrm{C}$ for $1 \mathrm{~min}$, with a final extension at $72{ }^{\circ} \mathrm{C}$ for 10 min. Negative control reactions lacking template DNA were performed in parallel. Amplified fragments were visualized on $1 \%$ agarose gels (FlashGel ${ }^{\text {TM }}$ System) and sequenced using the two PCR primers (Roche Diagnostics GmbH, Mannheim, Germany).

In order to deduce the phylogeny of the fungal isolates, the sequences ITS and TEF-1 a were compared with data available at the public database Genbank by using the BLASTn sequence match algorythm [71]. The best hits for each species retrieved from the BLAST search were retained and used to construct phylogenetic trees. Sequences were aligned using the CLUSTAL W program [72], and phylogenetic and molecular evolutionary analyses were conducted using MEGA X [73]. The phylogenetic tree was constructed using the neighbour-joining algorithm [74] with bootstrap values calculated from 1000 replicates [59].

The fungal strains were deposited at the Spanich type culture collection (CECT) under the reference numbers : CECT 21166, CECT 21167 and CECT 21168 for Trichoderma asperellum 1, 2 and 3 respectively, CECT 21164 for Stemphylium lucomagnoense and CECT 21165 for Aspergillus nidulans. 


\section{Fungal cultures}

Selected marine fungal strains were grown in submerged cultures in $50 \mathrm{~mL}$ M7-medium, and culture supernartant was used to retrieve ABTS-oxidizing, laccase-like activity as previously described [75]. $50 \mathrm{~mL}$ of 3-day precultures of fungal mycelia were vortexed using glass beads $(0.6 \mathrm{~mm})$ for $1 \mathrm{~min}$. The homogenized mycelial fragments were used to inoculate $250 \mathrm{~mL}$ Erlenmeyer flasks containing $50 \mathrm{~mL}$ of M7-medium. The medium (M7) contained ( $\left.\mathrm{g} \mathrm{L}^{-1}\right)$ : glucose, 5; peptone, 5; yeast extract, 1 ; ammonium tartrate, $2 ; \mathrm{KH}_{2} \mathrm{PO}_{4}, 1 ; \mathrm{MgSO}_{4-} 7 \mathrm{H}_{2} \mathrm{O}, 0.5 ; \mathrm{KCl}, 0.5$; trace element solution, $1 \mathrm{~mL}$. The trace element solution composition was as follows ( $\left.\mathrm{g} \mathrm{L}^{-1}\right)$ : $\mathrm{B}_{4} \mathrm{O}_{7} \mathrm{Na}_{2-} 10 \mathrm{H}_{2} \mathrm{O}, 0.1$; $\mathrm{CuSO}_{4-} 5 \mathrm{H}_{2} \mathrm{O}, 0.01 ; \mathrm{FeSO}_{4-} 7 \mathrm{H}_{2} \mathrm{O}, 0.05$; $\mathrm{MnSO}_{4-} 7 \mathrm{H}_{2} \mathrm{O}, 0.01 ; \mathrm{ZnSO}_{4-} 7 \mathrm{H}_{2} \mathrm{O}, 0.07 ;\left(\mathrm{NH}_{4}\right)_{6} \mathrm{Mo}_{7} \mathrm{O}_{24-} 4 \mathrm{H}_{2} \mathrm{O}, 0.01$. The final $\mathrm{pH}$ was adjusted to 5.5. The cultures were incubated at $30^{\circ} \mathrm{C}$ and $160 \mathrm{rpm}$ and aliquots were withdrawn daily. $\mathrm{Cu}^{2+}$ induction was performed in M7 medium supplemented with $2 \mathrm{mM} \mathrm{CuSO}_{4}$.

\section{Laccase-like activity assay}

Laccase-like activity was measured by monitoring the oxidation of $5 \mathrm{mM} \mathrm{ABTS}$ (Sigma-Aldrich) in $0.1 \mathrm{M}$ citrate phosphate buffer $(\mathrm{pH} 5)$ at $436 \mathrm{~nm}$ for 1 min [76]. The reaction mixture $(1 \mathrm{~mL})$ contained $0.1 \mathrm{~mL}$ supernatant of the culture medium which was centrifuged for $10 \mathrm{~min}$ at $12000 \mathrm{rpm}$. Oxidase activity was determined as the increase in absorbance at $436 \mathrm{~nm}\left[\left(\varepsilon_{436 \mathrm{~nm}}=29300 \mathrm{M}^{-1} \mathrm{~cm}^{-1}\right)\right.$ [77]. One unit of ABTSoxidizing activity is defined as the amount of enzyme needed to oxidize $1 \mu \mathrm{mol}$ of ABTS per minute at room temperature. Measurements were also conducted in the presence of either $\mathrm{H}_{2} \mathrm{O}_{2}(0.5 \mathrm{mM})$ or catalase (280 unit per $\mathrm{ml}$ of assay), in order to confirm that no activity was due to heme-containing peroxidases.

\section{Influence of $\mathrm{NaCl}$, sea salt, $\mathrm{CuSO}_{4}$ and different carbon sources on laccase-like activity}

To compare the effect of $\mathrm{NaCl}$ and sea salt on the production of active secretomes, standard $\mathrm{M} 7$ medium was supplemented with increasing concentrations of either $\mathrm{NaCl}$ or sea salt ( 1 to $5 \% \mathrm{w} / \mathrm{v}) .50 \mathrm{~mL}$ cultures were grown in $250 \mathrm{~mL}$ erlenmeyer flasks for a period of 7 days at $30^{\circ} \mathrm{C}$, and samples were withdrawn periodically. $\mathrm{CuSO}_{4}$ was also supplemented to cultures as an inducer of laccase-like activity in case LMCOs were involved. In order to find out the suitable concentration of $\mathrm{CuSO}_{4}$ for an optimal production of LMCOs, the following concentrations of $\mathrm{CuSO}_{4}$ were tested: $800 \mu \mathrm{M}, 1000 \mu \mathrm{M}, 1800 \mu \mathrm{M}$ and $2000 \mu \mathrm{M}$. In order to find the suitable carbon source for highest laccase-like activity in culture secretomes, the effect of different carbon sources, such as sucrose, glucose and starch was studied. The carbon sources were tested at a concentration of $3 \%$ in M7 production medium. The Erlenmeyer flasks $(250 \mathrm{~mL})$ containing 50 $\mathrm{mL}$ of the production medium were incubated at $30^{\circ} \mathrm{C}$ for a period of 7 days.

\section{Dye decolorization by Trichoderma asperellum 1 secretome}


To test the ability of $T$. asperellum 1 cultures to decolorize industrial dyes, five different dyes used in textile industry were selected: Remazol Brilliant Blue R (RBBR), Reactive Black 5 (RB5), Direct Red 75 (DR75), Acid Orange 51 (A051) and the Turquoise Blue (TB). Dyes were solubilized in water at a concentration of $500 \mathrm{mg} \mathrm{L}^{-1}$. Each dye was incubated at $30^{\circ} \mathrm{C}$ in $0.1 \mathrm{M}$ phosphate-citrate buffer $\mathrm{pH} 5.0$ at a final concentration of $50 \mathrm{mg} \mathrm{L}^{-1}$, together with aliquots of culture supernatant accouting for total ABTSoxidizing activity of $0.6 \mathrm{UL}^{-1}$, in a final volume of $1 \mathrm{~mL}$. Measurements were conducted in the presence or absence of $1 \mathrm{mM}$ 1-hydroxybenzotriazole (HBT), a commonly used laccase redox mediator, to test the oxidative activity of fungal secretomes. Color disappearance was monitored at the maximum absorbance wavelength for each dye $(585,597,520,438$ and $606 \mathrm{~nm}$ for RBBR, RB5, DR75, AO51 and the TB respectively). For each reaction mixture absorbance was recorded at 1, 2, 3, 4, 5, 24 and $48 \mathrm{~h}$. The percentage of decolorization was calculated by taking the maximum absorbance of each untreated dye solution as the control (100\% color). Optical density was measured using an Optizen Pop QX UV/Vis Spectrophotometer (Klab, King of Prussia, USA). All experiments were performed in triplicate.

Decolorization was defined as the percentage of absorbance loss compared to the control, untreated dye solution (defined as $100 \%$ absorbance, ABSORBANCE t0), using the formula:

decolorization $(\%)=$

(ABSORBANCE t0-ABSORBANCE tf) $* 100$

ABSORBANCET0

\section{Abbreviations}

asperellum : Trichoderma asperellum; A. nidulans : Aspergillus nidulans; S. lucomagnoense:

Stemphylium lucomagnoense; HBT : 1-hydroxybenzotriazole; LMCO : laccase-like multicopper oxidases; DMP : 2,6-dimethoxyphenol; ABTS : 2,2'-azino-bis-(3-ethylbenzthiazoline-6-sulfonic acid); PDA : potato dextrose agar; ITS : the internal transcribed spacer region; TEF-1 $a$ : translation elongation factor1 a region; RBBR : Remazol Brilliant Blue R; RB5 : Reactive Black 5; DR75 : Direct Red 75; A051 : Acid Orange 51; TB : Turquoise Blue; CECT : Spanish Type Culture Collection; $\mathrm{H}_{2} \mathrm{O}_{2}$ : Hydrogen Peroxide; $\mathrm{h}$ : Hour.

\section{References}

1. Rao MA, Scelza R, Scotti R, Gianfreda L. ROLE OF ENZYMES IN THE REMEDIATION OF POLLUTED ENVIRONMENTS. Journal of soil science and plant nutrition. 2010;10:333-53. 
2. Rodriguez-Couto S. Decolouration of industrial azo dyes by crude laccase from Trametes hirsuta. 2007.

3. Couto SR, Herrera JLT. Laccases in pollution control. Terrestrial and Aquatic Environmental Toxicology. 2007;1:34-45.

4. Ellouze M, Sayadi S. White-Rot Fungi and their Enzymes as a Biotechnological Tool for Xenobiotic Bioremediation. 2016.

5. Kohlmeyer J, Volkmann-Kohlmeyer B. FUNGI FROM CORAL REEFS: A COMMENTARY. Mycological Research. 2003;107:386-7.

6. Li Q, Wang G. Diversity of fungal isolates from three Hawaiian marine sponges. Microbiological Research. 2009;164:233-41.

7. Osterhage $\mathrm{C}$. Isolation, structure determination and biological activity assessment of secondary metabolites from marine-derived fungi. 2001.

8. Jones EBG, Pang K-L, Abdel-Wahab MA, Scholz B, Hyde KD, Boekhout T, et al. An online resource for marine fungi. Fungal Diversity. 2019;96:347-433.

9. Bonugli-Santos RC, Dos Santos Vasconcelos MR, Passarini MRZ, Vieira GAL, Lopes VCP, Mainardi $\mathrm{PH}$, et al. Marine-derived fungi: diversity of enzymes and biotechnological applications. Frontiers in microbiology. 2015;6:269.

10. Reiss R, Ihssen J, Richter M, Eichhorn E, Schilling B, Thöny-Meyer L. Laccase versus laccase-like multi-copper oxidase: a comparative study of similar enzymes with diverse substrate spectra. PloS one. 2013;8:e65633-e65633.

11. Kantharaj P, Boobalan B, Sooriamuthu S, Mani R. Lignocellulose Degrading Enzymes from Fungi and Their Industrial Applications. 2017.

12. M Mabrouk A, H Kheiralla Z, R Hamed E, A Youssry A, A Abd El Aty A. Characterization and kinetic properties of the purified Trematosphaeria mangrovei laccase enzyme. Saudi journal of biological sciences. 2013;20:373-81.

13. D'Souza-Ticlo D, Sharma D, Raghukumar C. A Thermostable Metal-Tolerant Laccase with Bioremediation Potential from a Marine-Derived Fungus. Marine Biotechnology. 2009;11:725-37.

14. Raghukumar C, D'Souza-Ticlo D, Verma A. Treatment of Colored Effluents with Lignin-Degrading Enzymes: An Emerging Role of Marine-Derived Fungi. Critical Reviews in Microbiology. 2008;34:189206.

15. Woudenberg JHC, Hanse B, van Leeuwen GCM, Groenewald JZ, Crous PW. Stemphylium revisited. Studies in Mycology. 2017;87:77-103.

16. Camarero S, Ibarra D, Martínez MJ, Martínez AT. Lignin-derived compounds as efficient laccase mediators for decolorization of different types of recalcitrant dyes. Applied and environmental microbiology. 2005;71:1775-84.

17. Tavares APM, Cristóvão RO, Loureiro JM, Boaventura RAR, Macedo EA. Optimisation of reactive textile dyes degradation by laccase-mediator system. Journal of Chemical Technology \& 
Biotechnology: International Research in Process, Environmental \& Clean Technology. 2008;83:1609-15.

18. Dhouib A, Hamza M, Zouari H, Mechichi T, H'midi R, Labat M, et al. Autochthonous fungal strains with high ligninolytic activities from Tunisian biotopes. 2005.

19. Saleem M, Ali MS, Hussain S, Jabbar A, Ashraf M, Lee YS. Marine natural products of fungal origin. Natural Product Reports. 2007;24:1142-52.

20. Rateb ME, Ebel R. Secondary metabolites of fungi from marine habitats. Natural Product Reports. 2011;28:290-344.

21. Zhang C, Kim S-K. Research and application of marine microbial enzymes: status and prospects. Marine drugs. 2010;8:1920-34.

22. Newell SY. Established and potential impacts of eukaryotic mycelial decomposers in marine/terrestrial ecotones. Journal of Experimental Marine Biology and Ecology. 1996;200:187206.

23. Shanuja SK, Iswarya S, Gnanamani A. Marine fungal DHICA as a UVB protectant: Assessment under in vitro and in vivo conditions. Journal of Photochemistry and Photobiology B: Biology. 2018;179:139-48.

24. An C-Y, Li X-M, Li C-S, Wang M-H, Xu G-M, Wang B-G. Aniquinazolines A-D, four new quinazolinone alkaloids from marine-derived endophytic fungus Aspergillus nidulans. Marine drugs. 2013;11:268294.

25. Xu J, Liu P, Li X, Gan L, Wang P. Novel Stemphol Derivatives from a marine fungus Pleospora sp. Natural Product Research. 2019;33:367-73.

26. Inderbitzin P, Kohlmeyer J, Volkmann-Kohlmeyer B, L Berbee M. Decorospora, a New Genus for the Marine Ascomycete Pleospora gaudefroyi. 2002.

27. Schoch CL, Seifert KA, Huhndorf S, Robert V, Spouge JL, Levesque CA, et al. Nuclear ribosomal internal transcribed spacer (ITS) region as a universal DNA barcode marker for Fungi. Proceedings of the National Academy of Sciences of the United States of America. 2012;109:6241-6.

28. Stielow JB, Lévesque CA, Seifert KA, Meyer W, Iriny L, Smits D, et al. One fungus, which genes? Development and assessment of universal primers for potential secondary fungal DNA barcodes. Persoonia. 2015;35:242-63.

29. Wu Q, Sun R, Ni M, Yu J, Li Y, Yu C, et al. Identification of a novel fungus, Trichoderma asperellum GDFS1009, and comprehensive evaluation of its biocontrol efficacy. PLOS ONE. 2017;12:e0179957.

30. Shi Z-Z, Fang S-T, Miao F-P, Yin X-L, Ji N-Y. Trichocarotins A-H and trichocadinin A, nine sesquiterpenes from the marine-alga-epiphytic fungus Trichoderma virens. Bioorganic Chemistry. 2018;81:319-25.

31. Pang $X$, Lin $X$, Tian $Y$, Liang $R$, Wang J, Yang B, et al. Three new polyketides from the marine spongederived fungus Trichoderma sp. SCSI041004. Natural product research. 2017;32:105-11. 
32. Korkmaz MN, Ozdemir SC, Uzel A. Xylanase production from marine derived Trichoderma pleuroticola $08 C ̧ K 001$ strain isolated from Mediterranean coastal sediments. Journal of Basic Microbiology. 2017;57:839-51.

33. Zhang L, Niaz SI, Wang Z, Zhu Y, Lin Y, Li J, et al. a-Glucosidase inhibitory and cytotoxic botryorhodines from mangrove endophytic fungus Trichoderma sp. 307. Natural Product Research. 2018;32:2887-92.

34. Song Y-P, Miao F-P, Fang S-T, Yin X-L, Ji N-Y. Halogenated and Nonhalogenated Metabolites from the Marine-Alga-Endophytic Fungus Trichoderma asperellum cf44-2. Marine drugs. 2018;16:266.

35. Ren J, Yang Y, Liu D, Chen W, Proksch P, Shao B, et al. Sequential determination of new peptaibols asperelines G-Z12 produced by marine-derived fungus Trichoderma asperellum using ultrahigh pressure liquid chromatography combined with electrospray-ionization tandem mass spectrometry. Journal of Chromatography A. 2013;1309:90-5.

36. Levasseur A, Saloheimo M, Navarro D, Andberg M, Pontarotti P, Kruus K, et al. Exploring laccase-like multicopper oxidase genes from the ascomycete Trichoderma reesei: a functional, phylogenetic and evolutionary study. BMC biochemistry. 2010;11:32.

37. Bagewadi ZK, Mulla SI, Ninnekar HZ. Purification and immobilization of laccase from Trichoderma harzianum strain HZN10 and its application in dye decolorization. Journal of Genetic Engineering and Biotechnology. 2017;15:139-50.

38. Gochev VK, Krastanov Al. Isolation of laccase producing Trichoderma spp. Bulgarian Journal of Agricultural Science. 2007;13:171.

39. Zafra G, Moreno-Montaño A, Absalón ÁE, Cortés-Espinosa D V. Degradation of polycyclic aromatic hydrocarbons in soil by a tolerant strain of Trichoderma asperellum. Environmental Science and Pollution Research. 2015;22:1034-42.

40. Saravanakumar K, Kathiresan K. Bioremoval of the synthetic dye malachite green by marine Trichoderma sp. SpringerPlus. 2014;3:631.

41. Raghukumar C. Marine fungal biotechnology: An ecological perspective. 2008.

42. Theerachat M, Guieysse D, Morel S, Remaud-Siméon M, Chulalaksananukul W. Laccases from Marine Organisms and Their Applications in the Biodegradation of Toxic and Environmental Pollutants: a Review. Applied Biochemistry and Biotechnology. 2019;187:583-611.

43. D'Souza DT, Tiwari R, Sah AK, Raghukumar C. Enhanced production of laccase by a marine fungus during treatment of colored effluents and synthetic dyes. Enzyme and Microbial Technology. 2006;38:504-11.

44. Wikee S, Hatton J, Turbé-Doan A, Mathieu Y, Daou M, Lomascolo A, et al. Characterization and Dye Decolorization Potential of Two Laccases from the Marine-Derived Fungus Pestalotiopsis sp. International journal of molecular sciences. 2019;20:1864.

45. Paul S, Bag SK, Das S, Harvill ET, Dutta C. Molecular signature of hypersaline adaptation: insights from genome and proteome composition of halophilic prokaryotes. Genome biology. 2008;9:R70R70. 
46. Collins PJ, Dobson A. Regulation of Laccase Gene Transcription in Trametes versicolor. Applied and environmental microbiology. 1997;63:3444-50.

47. Domínguez A, Gómez J, Lorenzo M, Sanromán Á. Enhanced production of laccase activity by Trametes versicolor immobilized into alginate beads by the addition of different inducers. World Journal of Microbiology and Biotechnology. 2007;23:367-73.

48. Palmieri G, Giardina P, Bianco C, Fontanella B, Sannia G. Copper induction of laccase isoenzymes in the ligninolytic fungus Pleurotus ostreatus. Applied and environmental microbiology. 2000;66:920-4.

49. Hao J, Song F, Huang F, Yang C, Zhang Z, Zheng Y, et al. Production of laccase by a newly isolated deuteromycete fungus Pestalotiopsis sp. and its decolorization of azo dye. Journal of Industrial Microbiology \& Biotechnology. 2006;34:233.

50. Nakade K, Nakagawa Y, Yano A, Konno N, Sato T, Sakamoto Y. Effective induction of pblac1 laccase by copper ion in Polyporus brumalis ibrc05015. Fungal Biology. 2013;117:52-61.

51. Piscitelli A, Giardina P, Lettera V, Pezzella C, Sannia G, Faraco V. Induction and transcriptional regulation of laccases in fungi. Current genomics. 2011;12:104-12.

52. Galhaup C, Wagner H, Hinterstoisser B, Haltrich D. Increased production of laccase by the wooddegrading basidiomycete Trametes pubescens. Enzyme and Microbial Technology. 2002;30:529-36.

53. Kaal E, Field J, Joyce T. Increasing Ligninolytic Enzyme Activities in Several White-Rot Basidomycetes by Nitrogen-Sufficient Media. 1995.

54. Afreen S, Anwer R, Singh RK, Fatma T. Extracellular laccase production and its optimization from Arthrospira maxima catalyzed decolorization of synthetic dyes. Saudi Journal of Biological Sciences. 2018;25:1446-53.

55. Stolz A. Basic and Applied Aspects in the Microbial Degradation of Azo Dyes. 2001.

56. Husain Q. Potential Applications of the Oxidoreductive Enzymes in the Decolorization and Detoxification of Textile and Other Synthetic Dyes from Polluted Water: A Review. Critical Reviews in Biotechnology. 2006;26:201-21.

57. Young L, Yu J. Ligninase-catalysed decolorization of synthetic dyes. Water Research. 1997;31:118793.

58. O’Neill C, Hawkes FR, Hawkes DL, Lourenço ND, Pinheiro HM, Delée W. Colour in textile effluents sources, measurement, discharge consents and simulation: a review. Journal of Chemical Technology \& Biotechnology. 1999;74:1009-18.

59. Bonugli-Santos RC, Durrant LR, da Silva M, Sette LD. Production of laccase, manganese peroxidase and lignin peroxidase by Brazilian marine-derived fungi. Enzyme and Microbial Technology. 2010;46:32-7.

60. Abadulla E, Robra K-H, M. Gubitz G, M. Silva L, Cavaco-Paulo A. Enzymatic Decolorization of Textile Dyeing Effluents. 2000.

61. Levine WG. Metabolism of AZO Dyes: Implication for Detoxication and Activation. Drug Metabolism Reviews. 1991;23:253-309. 
62. Forootanfar H, Moezzi A, Aghaie-Khozani M, Mahmoudjanlou Y, Ameri A, Niknejad F, et al. Synthetic dye decolorization by three sources of fungal laccase. Iranian journal of environmental health science \& engineering. 2012;9:27.

63. Mechichi T, Mhiri N, Sayadi S. Remazol Brilliant Blue R decolourization by the laccase from Trametes trogii. Chemosphere. 2006;64:998-1005.

64. Raghukumar C, D'Souza TM, Thorn RG, Reddy CA. Lignin-Modifying Enzymes of \&lt;em\&gt;Flavodon flavus\&lt;/em\&gt; a Basidiomycete Isolated from a Coastal Marine Environment. Applied and Environmental Microbiology. 1999;65:2103 LP - 2111.

65. Divya LM, Prasanth GK, Sadasivan C. Isolation of a salt tolerant laccase secreting strain of Trichoderma sp. NFCCl-2745 and optimization of culture conditions and assessing its effectiveness in treating saline phenolic effluents. Journal of Environmental Sciences. 2013;25:2410-6.

66. Adnan LA, Sathishkumar P, Mohd Yusoff AR, Hadibarata T. Metabolites characterisation of laccase mediated Reactive Black 5 biodegradation by fast growing ascomycete fungus Trichoderma atroviride F03. International Biodeterioration \& Biodegradation. 2015;104:274-82.

67. Daâssi D, Zouari-Mechichi H, Frikha F, Martinez MJ, Nasri M, Mechichi T. Decolorization of the azo dye Acid Orange 51 by laccase produced in solid culture of a newly isolated Trametes trogii strain. 3 Biotech. 2013;3:115-25.

68. Plácido J, Chanagá X, Ortiz-Monsalve S, Yepes M, Mora A. Degradation and detoxification of synthetic dyes and textile industry effluents by newly isolated Leptosphaerulina sp. from Colombia. Bioresources and Bioprocessing. 2016;3:6.

69. Saroj S, Kumar K, Pareek N, Prasad R, Singh RP. Biodegradation of azo dyes Acid Red 183, Direct Blue 15 and Direct Red 75 by the isolate Penicillium oxalicum SAR-3. Chemosphere. 2014;107:2408.

70. White T, Bruns T, Lee S, Taylor J, Innis M, Gelfand D, et al. Amplification and Direct Sequencing of Fungal Ribosomal RNA Genes for Phylogenetics. In: Pcr Protocols: a Guide to Methods and Applications,. 1990. p. 315-22.

71. Altschul SF, Madden TL, Schäffer AA, Zhang J, Zhang Z, Miller W, et al. Gapped BLAST and PSIBLAST: a new generation of protein database search programs. Nucleic acids research. 1997;25:3389-402.

72. Thompson JD, Higgins DG, Gibson TJ. CLUSTAL W: improving the sensitivity of progressive multiple sequence alignment through sequence weighting, position-specific gap penalties and weight matrix choice. Nucleic acids research. 1994;22:4673-80.

73. Kumar S, Stecher G, Li M, Knyaz C, Tamura K. MEGA X: Molecular Evolutionary Genetics Analysis across Computing Platforms. Molecular Biology and Evolution. 2018;35:1547-9.

74. Gascuel O. BIONJ: an improved version of the $\mathrm{NJ}$ algorithm based on a simple model of sequence data. Molecular Biology and Evolution. 1997;14:685-95.

75. Zouari-Mechichi H, Mechichi T, Dhouib A, Sayadi S, Martínez AT, Martínez MJ. Laccase purification and characterization from Trametes trogii isolated in Tunisia: decolorization of textile dyes by the 
purified enzyme. Enzyme and Microbial Technology. 2006;39:141-8.

76. More SS, P S R, K P, M S, Malini S, S M V. Isolation, Purification, and Characterization of Fungal Laccase from Pleurotus sp. Enzyme research. 2011;2011:248735. doi:10.4061/2011/248735.

77. Mansur M, Arias ME, Copa-Patiño JL, Flärdh M, González AE. The white-rot fungus Pleurotus ostreatus secretes laccase isozymes with different substrate specificities. Mycologia. 2003;95:101320.

\section{Declarations}

\section{Ethics approval and consent to participate}

Not applicable

Consent for publication

Not applicable

\section{Availability of data and materials}

All data generated and anylzed during this study are included in the published article. The fungal strains were deposited at the Spanich type culture collection (CECT) under the reference numbers: CECT 21166, CECT 21167 and CECT 21168 for Trichoderma asperellum 1, 2 and 3 respectively, CECT 21164 for Stemphylium lucomagnoense and CECT 21165 for Aspergillus nidulans.

\section{Permission to collect samples}

No permission was necessary to collect samples.

\section{Competing interests}

The authors declare there is no Conflict of interest.

\section{Funding}

This work was partially funded by PHC-Utique (39274UH 2018-2020, 18G0817) by a grant to Wissal BEN ALI.

\section{Author's contributions}

Wissal BEN ALI carried out the fungal collection and isolation, fungal cultures, enzyme tests and dye decolorization. DC and DN performed molecular marker amplification and contributed to fungal identification. CL and LLM managed the phylogenetic and morphological analysis of the fungal strains. ATD contributes to enzyme screening. EB, CBF, GS, TM and ER conceived and supervised the experiments, 
wrote the manuscript with Wissal BEN ALI. All authors have read and approved the final version of the manuscript.

\section{Author details}

${ }^{1}$ Université de Sfax, Ecole Nationale d'Ingénieurs de Sfax, Laboratoire de Biochimie et de Génie enzymatique des lipases, Tunisia

${ }^{2}$ Aix-Marseille Université, INRA UMR1163, Biodiversité et Biotechnologie Fongiques, Marseille, France

${ }^{3}$ INRA, Aix-Marseille Université, UMR1163, CIRM-CF, Marseille, France

${ }^{4}$ Ascofrance, 64 route de Chizé, F-79360 Villiers en Bois, France

Aknowledgements: The authors would like to thank PHC-Utique (39274UH 2018-2020, 18G0817) for financial support.

\section{Figures}

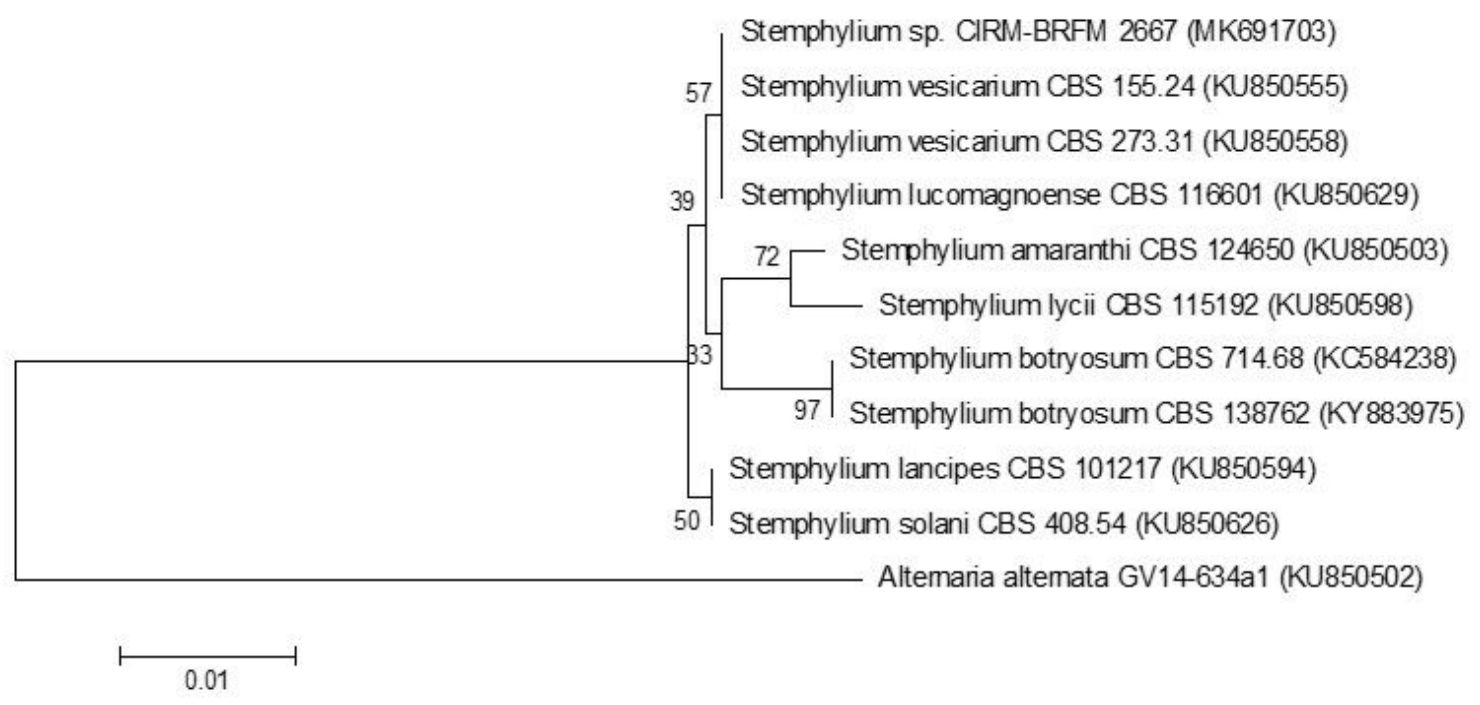

Fig. 1

Figure 1 
Phylogenetic reconstruction for the strain Stemphylium sp, based on ITS analysis using neighbour-joining algorithm (NJ) method and 1000 replicate boostraps, ITS sequences were deposited in the NCBI under accession number MK691703.

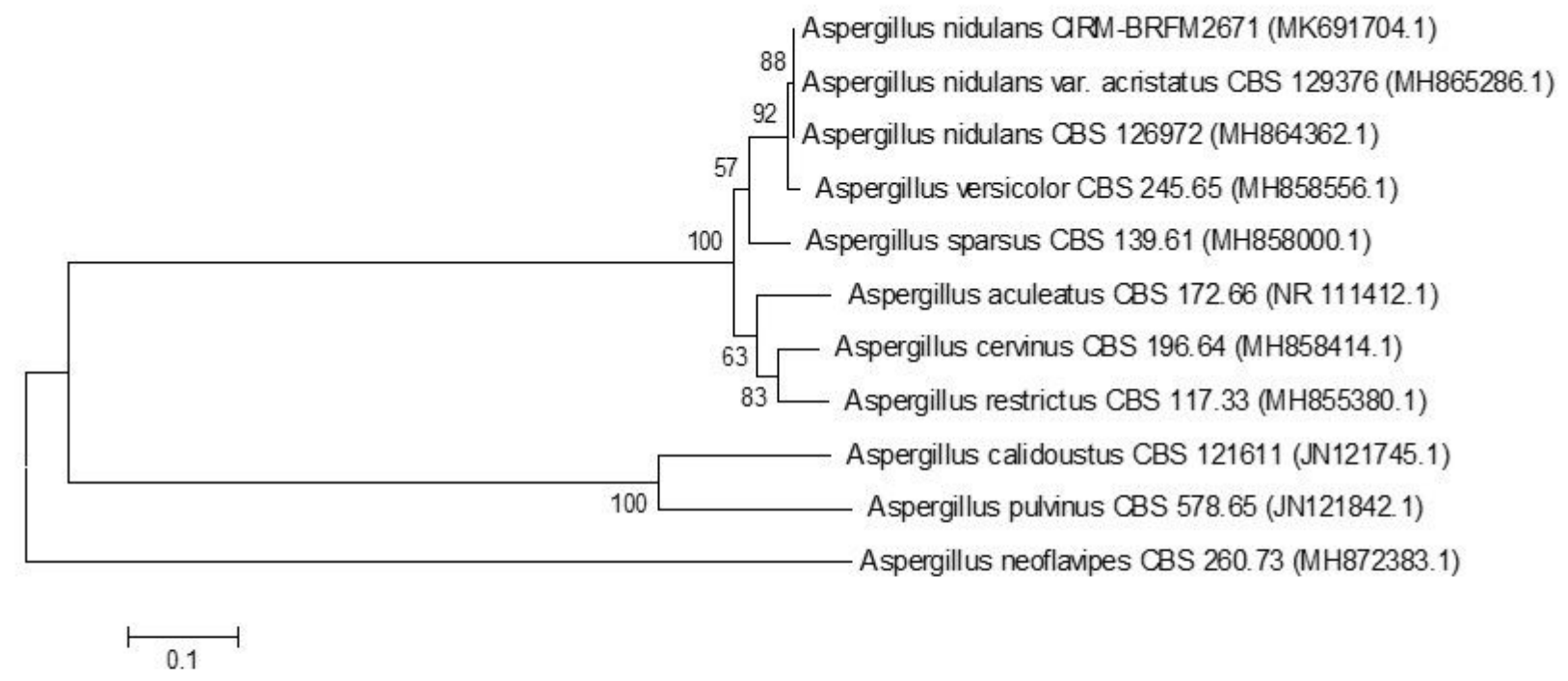

Fig. 2

\section{Figure 2}

Phylogenetic reconstruction for the strain Aspergillus sp, based on ITS analysis using neighbour-joining algorithm (NJ) method and 1000 replicate boostraps, ITS sequences were deposited in the NCBI under accession numbers MK691704. 


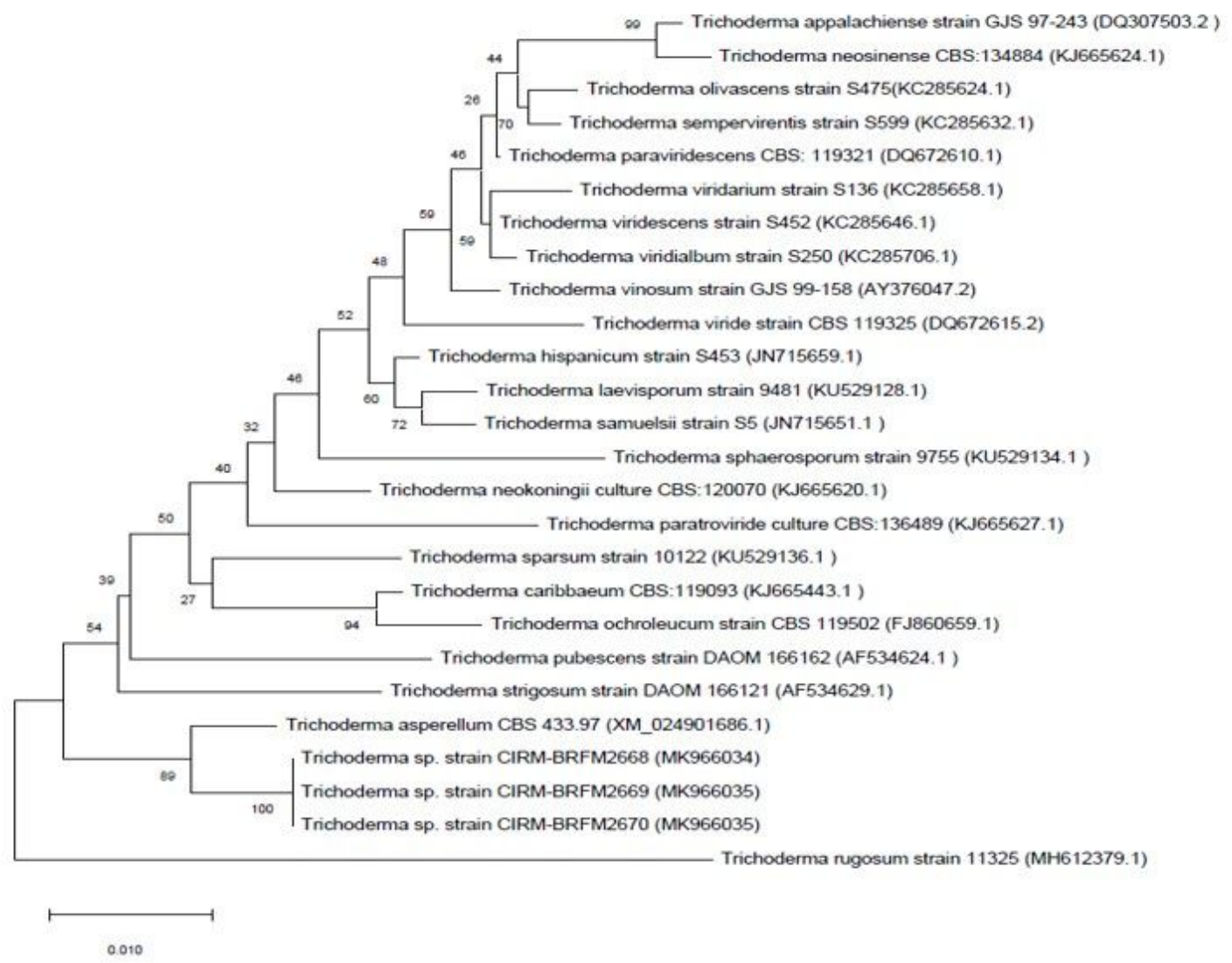

Fig. 3

\section{Figure 3}

Phylogenetic reconstruction for the strain Trichoderma asperellum 1, 2 and 3 based on elongation factor 1-alpha (EF1a) analysis using neighbour-joining algorithm ( $\mathrm{NJ}$ ) method and 1000 replicate boostraps (MK966034, MK966035 and MK966036 are the accession number of Trichoderma 1, 2 and 3 respectively). 


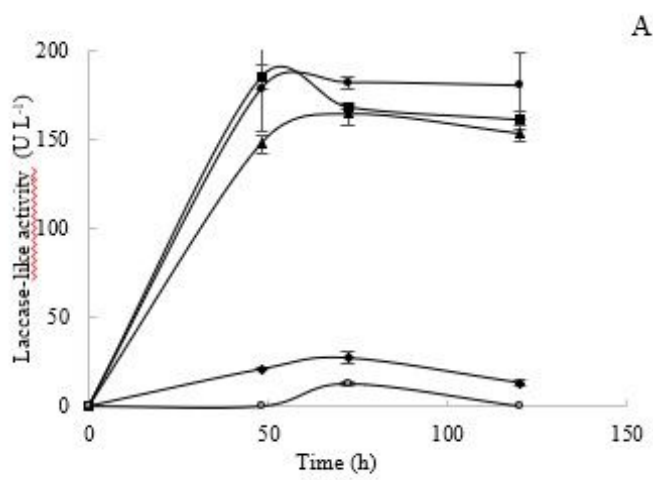

A

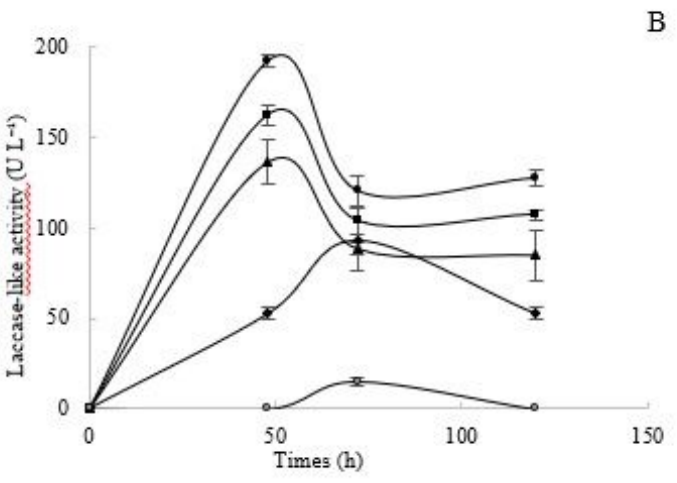

Fig. 4

\section{Figure 4}

(A) Laccase activity of Trichoderma asperellum $1(\mathbf{\bullet})$, Trichoderma asperellum $2(\boldsymbol{\square})$, Trichoderma asperellum $3(\boldsymbol{\Delta})$, Stemphylium lucomagnoense $(\boldsymbol{\bullet})$ and Aspergillus nidulans $(\boldsymbol{\bullet})$ during five days of culture with ABTS as the subtrate at pH 5.5 without (A) or with (B) $1 \% \mathrm{NaCl}$. Each data point (mean +/standard deviation) is the result of triplicate experiments. 

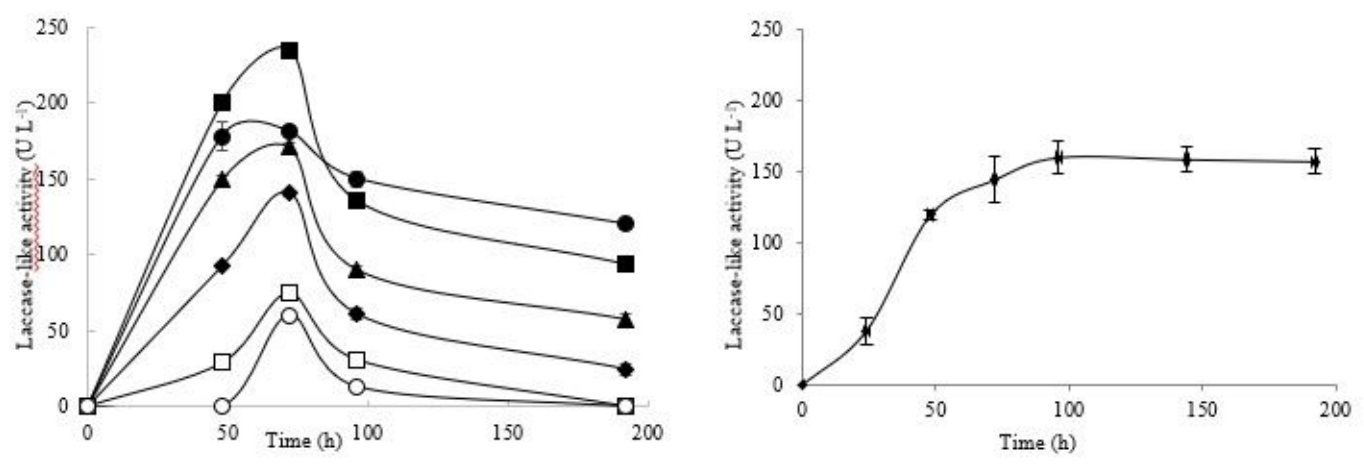

Fig. 5

\section{Figure 5}

(A) Effect of different concentration of $\mathrm{NaCl}(0 \%(\bullet), 1 \%(\boldsymbol{\square}), 2 \%(\boldsymbol{\Delta}), 3 \%(\bullet), 4 \%(\square)$ and $5 \%(\boldsymbol{\bullet}))$ on Trichoderma asperellum 1 laccase production (B) Effect of $1 \%$ of sea salt on T. asperellum 1 laccase-like production. Each data point (mean $+/$ - standard deviation) is the result of triplicate experiments. 


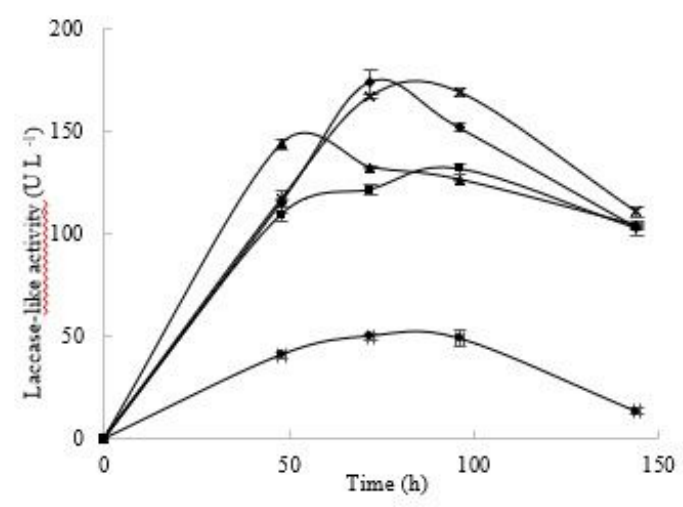

Fig. 6

Figure 6

Effect of different concentation of CuSO4 (0 mM (⿶), $0.8 \mathrm{mM}(\boldsymbol{\square}), 1 \mathrm{mM}(\boldsymbol{\Delta}), 1.8 \mathrm{mM}(\diamond)$ and $2 \mathrm{mM}(*))$ on Trichoderma asperellum 1 laccase-like production. 

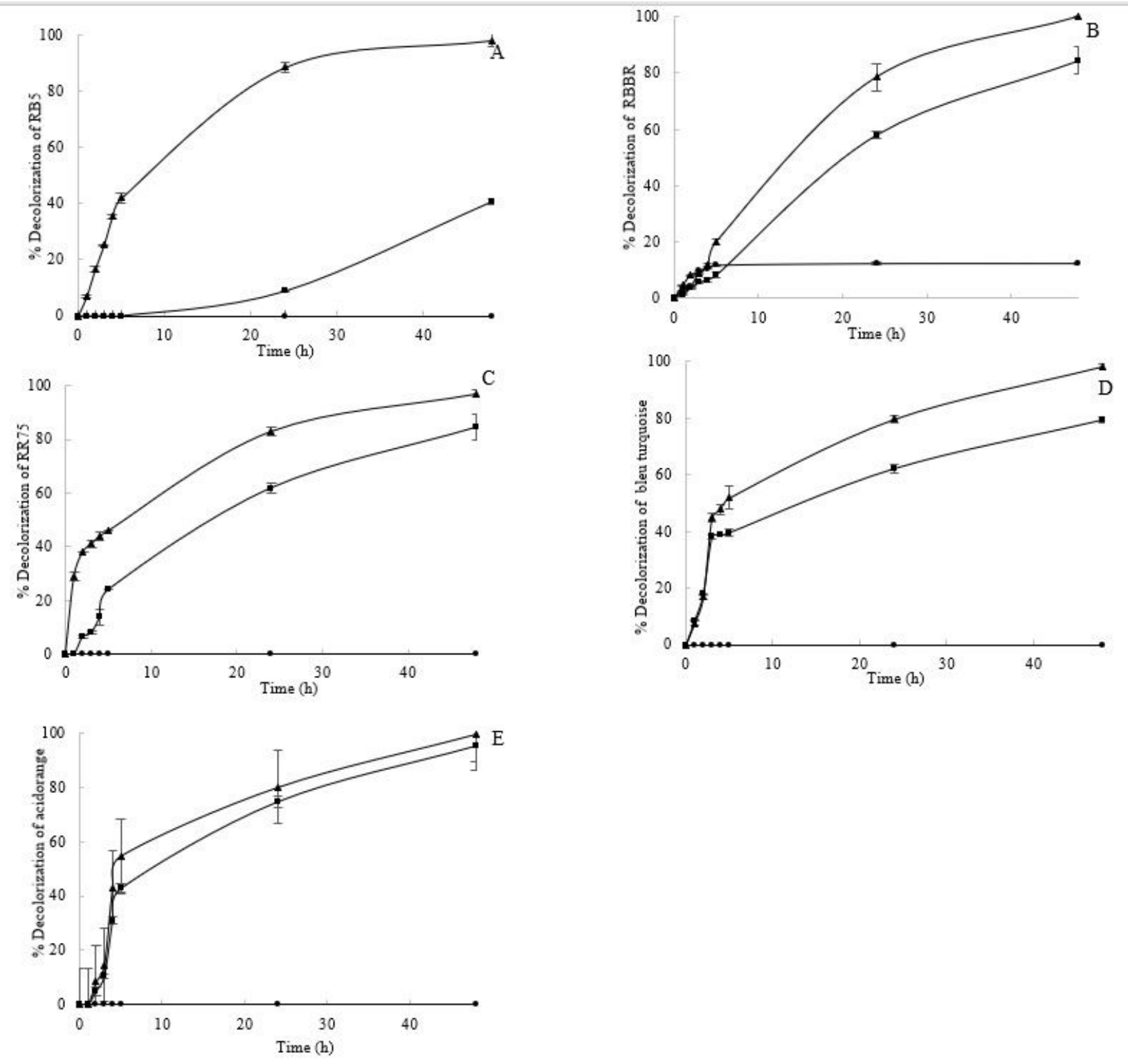

Fig. 7

\section{Figure 7}

Decolorization of the five reactive dyes (50 $\mu \mathrm{g} / \mathrm{mL}$ each) namely industry Reactive Black 5 (RB5) (A), Remazol Brilliant Blue R (RBBR) (B), RR75 (C), Blue Turquoise (D) and Acid Orange (E) the within $48 \mathrm{~h}$ (\% of decolorization in the presence of 1-hydroxybenzotriazole (HBT) (O), \% of decolorization in the presence of enzyme $(\boldsymbol{\square})$ and \% of decolorization in the presence of enzyme and HBT $(\boldsymbol{\Delta}))$ ). The disappearance of the color by laccase-like enzyme was monitored at specific wavelengths $(585,597,520$, 438 and $606 \mathrm{~nm}$ ) with time (1, 2, 3, 4, 5, 24 and $48 \mathrm{~h}$ ). Each data point (mean +/- standard deviation) is the result of duplicate experiments.

\section{Supplementary Files}

This is a list of supplementary files associated with this preprint. Click to download. 
- fs1.jpg

Page 28/28 